\title{
Nephrogenic Cholestatic Jaundice
}

\section{Tara Kannan ${ }^{1}$ and Adel Ekladious ${ }^{2 *}$}

${ }^{1}$ Medical Student, School of Medicine and Public Health, University of Newcastle, Newcastle, NSW, Australia

${ }^{2}$ Associate professor, Internal Medicine Specialist, Faculty of Health and Medical Sciences, University of Western Australia, Perth, 35 Stirling Highway Crawly,

Western Australia

*Corresponding Author: Adel Ekladious, Associate professor, Internal Medicine Specialist, Faculty of Health and Medical Sciences, University of Western Australia, Perth, 35 Stirling Highway Crawly, Western Australia 6009. E-mail: ekladiou@gmail.com
Received: April 20, 2021

Published: June 16, 2021

(C) All rights are reserved by Tara Kannan and Adel Ekladious.

\section{Abstract}

Cholestasis due to liver metastasis is more common than primary liver carcinoma.

Common cancers that metastasize to the liver are colorectal cancer followed by breast and pancreas, to the best of our knowledge very few malignancies can cause paraneoplastic cholestasis which are renal cell carcinoma followed by lymphoproliferative disease and cancer prostate.

Stauffer syndrome is a paraneoplastic cholestasis due to renal cell carcinoma, commonly cause fever and cholestatic liver function in the absence of any metastatic involvement, treating renal cell carcinoma usually cures liver cholestasis.

We present a patient with fever and advanced renal cell carcinoma in the absence of liver involvement.

Due to end stage renal carcinoma and other comorbidity, patient and family opt to palliative management.

Keywords: Cholestasis; Liver Carcinoma; Lymphoproliferative Disease; Cancer Prostate

\section{Introduction}

A variety of paraneoplastic syndromes are seen in $20 \%$ of patients with renal cell carcinoma (RCC) [1]. Stauffer's syndrome is a rare paraneoplastic manifestation that is characterised by nonmetastatic hepatic dysfunction [1]. We present a case of Stauffer's syndrome as the first presentation of RCC.

\section{Case Report}

A 93-year-old female presented to the emergency department with a three-day history of jaundice, epigastric pain, anorexia, nausea and fever. Past medical and surgical history included cholelithiasis, humeral fracture and total shoulder replacement. She was a non-smoker and denied alcohol use. Abdominal examination showed distention, right upper quadrant tenderness but no palpable masses. Laboratory results showed bilirubin 55 umol/L (3 - 17 umol/L), alanine aminotransferase $42 \mathrm{U} / \mathrm{L}$ (7 - $55 \mathrm{U} / \mathrm{L}$ ), aspartate transaminase $587 \mathrm{U} / \mathrm{L}$ (8 - $48 \mathrm{U} / \mathrm{L})$, alkaline phosphatase $190 \mathrm{U} / \mathrm{L}$ ( 40 - $129 \mathrm{U} / \mathrm{L}$ ), gamma-glutamyl transferase $200 \mathrm{U} / \mathrm{L}$ (8 - $61 \mathrm{U} / \mathrm{L}$ ) and C-reactive protein $76 \mathrm{mg} / \mathrm{dL}(<0.5 \mathrm{mg} / \mathrm{dL})$. Contrast-enhanced computed tomography abdomen revealed a 64 x 71 x $99 \mathrm{~mm}$ right renal mass. This invaded into the right renal vein, inferior vena cava (Panel A, arrow), renal pelvis and proximal ureter, and abutted the right atrium (Panel B, arrow). No hepatic metastases or other reasons for her abnormal liver function tests (LFTs) were identified. 
The most likely explanation for this constellation of fever, deranged LFTs and renal mass is Stauffer's syndrome. Given the large mass and patient's advanced age, our patient was not for invasive management, such as biopsy and surgery, and was palliated.

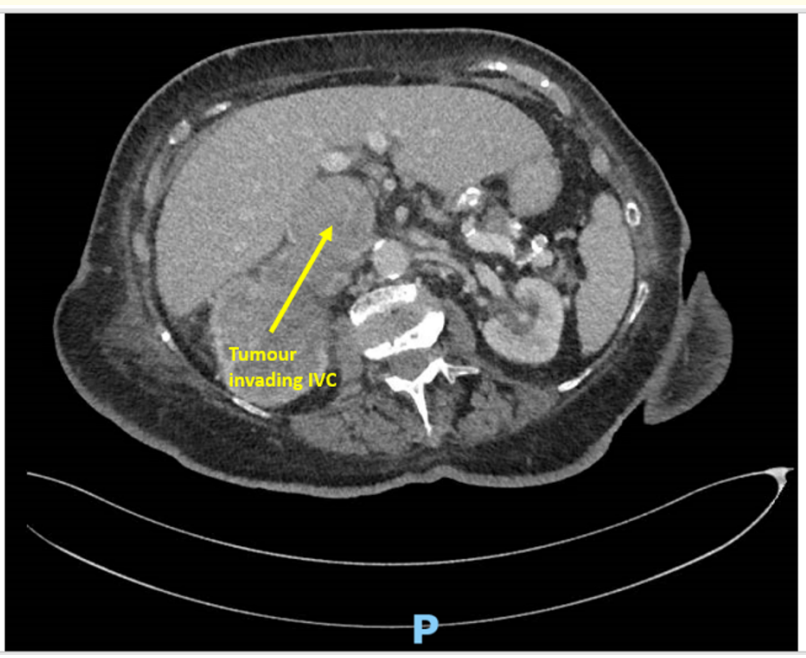

Panel A: With labels.

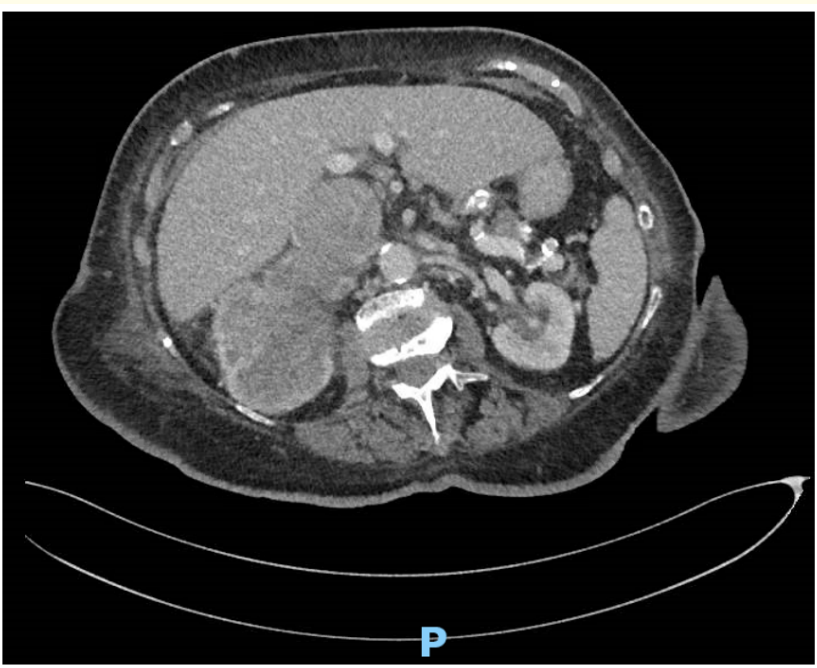

Panel A: Without labels.

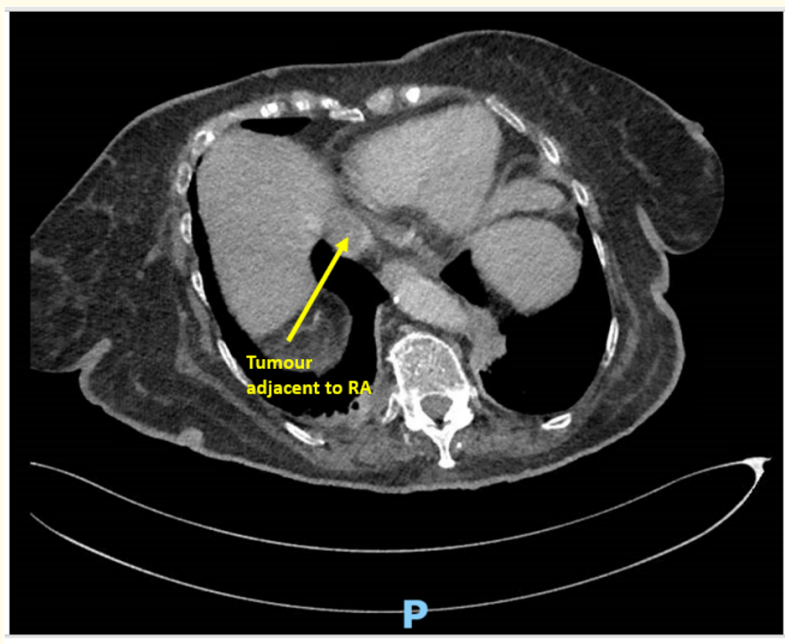

Panel B: With labels.

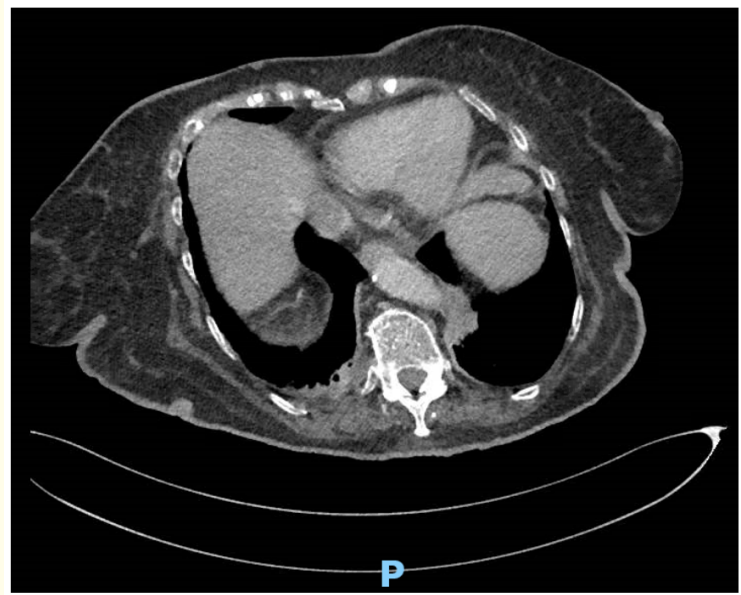

Panel B: Without labels.

\section{Discussion and Conclusion}

Stauffer's syndrome is a rare paraneoplastic manifestation of RCC, characterised by hepatic dysfunction without liver metastases [1]. It may be the initial and only presentation of RCC, as seen in our patient who had no other features such as haematuria or flank pain despite a large, extensive tumour [2]. Furthermore, ic- 
teric cholestasis is an even rarer variant of Stauffer's syndrome [3]. Differential diagnoses include viral hepatitis, primary biliary cholangitis and hepatic metastases. Nephrectomy results in complete recovery; while, immune checkpoint inhibitors, targeting the underlying mechanisms of interleukin 6 overexpression, may confer benefit in inoperable patients [1]. Clinicians should consider Stauffer's syndrome in their differential diagnosis for cholestatic jaundice, especially since it may be the only presentation of RCC and facilitate early diagnosis. It is paramount to exclude hepatic metastases which carries a poorer prognosis.

\section{Bibliography}

1. Fontes-Sousa Mário., et al. "Stauffer's syndrome: a comprehensive review and proposed updated diagnostic criteria". Urologic Oncology: Seminars and Original Investigations 36.7 (2018).

2. Kranidiotis Georgios P.., et al. "Stauffer's syndrome as a prominent manifestation of renal cancer: a case report". Cases Journal 2.1 (2009): 1-4.

3. Sharma Neha., et al. "Stauffer syndrome: a comprehensive review of the icteric variant of the syndrome". Cureus 11.10 (2019).

\section{Volume 5 Issue 7 July 2021}

(C) All rights are reserved by Tara Kannan and Adel Ekladious. 